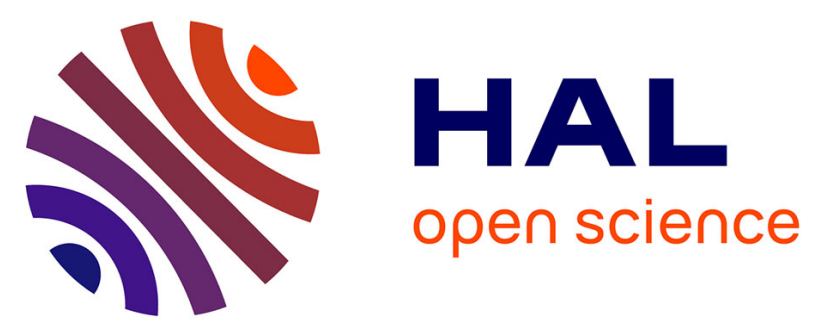

\title{
Speckle-Tracking Echocardiography in Children With Duchenne Muscular Dystrophy: A Prospective Multicenter Controlled Cross-Sectional Study
}

Pascal Amedro, Marie Vincenti, Gregoire de La Villeon, Kathleen Lavastre, Catherine Barrea, Sophie Guillaumont, Charlène Bredy, Lucie Gamon, Albano C Meli, Olivier Cazorla, et al.

\section{To cite this version:}

Pascal Amedro, Marie Vincenti, Gregoire de La Villeon, Kathleen Lavastre, Catherine Barrea, et al.. Speckle-Tracking Echocardiography in Children With Duchenne Muscular Dystrophy: A Prospective Multicenter Controlled Cross-Sectional Study. Journal of The American Society of Echocardiography, 2019, 10.1016/j.echo.2018.10.017 . hal-01996427

\section{HAL Id: hal-01996427 https://hal.science/hal-01996427}

Submitted on 22 Oct 2021

HAL is a multi-disciplinary open access archive for the deposit and dissemination of scientific research documents, whether they are published or not. The documents may come from teaching and research institutions in France or abroad, or from public or private research centers.
L'archive ouverte pluridisciplinaire HAL, est destinée au dépôt et à la diffusion de documents scientifiques de niveau recherche, publiés ou non, émanant des établissements d'enseignement et de recherche français ou étrangers, des laboratoires publics ou privés.

\section{(ㄷ)(1) $\$$}

Distributed under a Creative Commons Attribution - NonCommerciall 4.0 International 


\title{
Speckle-Tracking Echocardiography in Children With Duchenne Muscular Dystrophy: A Prospective Multicenter Controlled Cross-Sectional Study
}

\author{
Pascal Amedro, MD, PhD, Marie Vincenti, MD, Gregoire De La Villeon, MD, Kathleen Lavastre, MSc, \\ Catherine Barrea, MD, PhD, Sophie Guillaumont, MD, Charlene Bredy, MD, Lucie Gamon, MSc, \\ Albano C. Meli, PhD, Olivier Cazorla, PhD, Jeremy Fauconnier, PhD, Pierre Meyer, MD, \\ François Rivier, $\mathrm{MD}$, PhD, Jerome Adda, MD, Thibault Mura, MD, PhD, \\ and Alain Lacampagne, $\mathrm{PhD}$, Montpellier and Palavas-Les-Flots, France; and Brussels, Belgium
}

\begin{abstract}
Background: Prognosis of Duchenne muscular dystrophy (DMD) is related to cardiac dysfunction. Speckle-tracking echocardiographic (STE) imaging is emerging as a noninvasive functional biomarker to consider in the early detection of DMD-related cardiomyopathy. However, STE analysis has not been assessed in a prospectively controlled study, especially in presymptomatic children with DMD, and no study has used STE analysis in all three displacements (longitudinal, radial, and circumferential) and for both ventricles.
\end{abstract}

Methods: This prospective controlled study enrolled 108 boys, 36 of whom had DMD (mean age, $11 \pm 3.8$ years) and 72 of whom were age-matched control subjects in a 1:2 case-control design. Conventional echocardiographic variables were collected for the left and right ventricles. STE analyses were performed in the longitudinal, radial, and circumferential displacements for the left ventricle and in the free wall longitudinal displacement for the right ventricle. The effect of age on the evolution of two-dimensional strain in children with DMD was studied by adding an interaction term, DMD $\times$ age, in the models.

Results: Conventional echocardiographic measures were normal in both groups. Left ventricular (LV) ejection fraction ranged from $45 \%$ to $76 \%$ (mean, $63 \pm 6 \%$ ) in the DMD group and from $55 \%$ to $76 \%$ (mean, $64 \pm 5 \%$ ) in the control group. Global LV strain mean measures were significantly worse in the DMD group for the longitudinal $(-16.8 \pm 3.9 \%$ vs $-20.6 \pm 2.6 \%, P<.0001)$, radial $(22.7 \pm 11.3 \%$ vs $31.7 \pm 14 \%, P=.002)$, and circumferential $(-16.5 \pm 3.8 \%$ vs $-20.3 \pm 3.1 \%, P<.0001)$ displacements. The decrease of global LV longitudinal strain with age in children with DMD was $0.34 \%$ per year more marked than that in control subjects. The LV inferolateral and anterolateral segments were specifically impaired, especially in the basal area. Right ventricular function evaluated using conventional echocardiography and STE analysis was normal and not different between children with DMD and control subjects.

Conclusions: The existence of altered LV strain despite normal LV function in children with DMD represents an important perspective for future pediatric drug trials in DMD-related cardiomyopathy prevention. (J Am Soc Echocardiogr 2019;32:412-22.)

Keywords: Speckle-tracking, 2D strain, DMD, Pediatrics, Dilated cardiomyopathy

From the Pediatric and Congenital Cardiology Department, M3C Regional Reference CHD Center (P.A., M.V., G.D.L.V., K.L., S.G., C.B.), PHYMEDEXP, University of Montpellier, CNRS, INSERM (P.A., M.V., A.C.M., O.C., J.F., P.M., F.R., A.L.), the Epidemiology and Clinical Research Department (L.G., T.M.), the Clinical Investigation Center, University of Montpellier, INSERM (T.M.), Pediatric Neurology, National Reference Centre for Neuromuscular Diseases (P.M., F.R.), and the Department of Cardiology (C.B., J.A.), CHU Montpellier, Montpellier; Pediatric Cardiology and Rehabilitation Unit, St-Pierre Institute, Palavas-Les-Flots (M.V., G.D.L.V., S.G.), France; and the Pediatric and Congenital Cardiology Department, Cliniques Universitaires Saint-Luc, UCL University, Brussels, Belgium (C.B.).

412
This work was supported by grants from Montpellier University Hospital Clinical Research Institutional Grant (PHRC-MERRI UF 9458) and from the French National Muscular Dystrophy Association (AFM 20225).

Conflicts of Interest: None.

Reprint requests: Pascal Amedro, MD, PhD, Montpellier University Hospital, Pediatric and Congenital Cardiology Department, 371 Avenue du Doyen Giraud, 34295 Montpellier, France (E-mail: p-amedro@chu-montpellier.fr).

0894-7317/\$36.00

Copyright 2018 by the American Society of Echocardiography.

https://doi.org/10.1016/j.echo.2018.10.017

(C) 2019 published by Elsevier. This manuscript is made available under the CC BY NC user license https://creativecommons.org/licenses/by-nc/4.0/ 


\begin{tabular}{|l|}
\hline \multicolumn{1}{|c|}{ Abbreviations } \\
\hline 2D = Two-dimensional \\
CMR = Cardiovascular \\
magnetic resonance \\
DMD = Duchenne muscular \\
dystrophy \\
ICC = Intraclass correlation \\
coefficient \\
LV = Left ventricular \\
LVEF = Left ventricular \\
ejection fraction \\
RV = Right ventricular \\
STE = Speckle-tracking \\
echocardiographic \\
\hline
\end{tabular}

which usually occurs in the second decade. ${ }^{3}$ However, during childhood, the classical symptoms of heart failure are not present, and the severity of the cardiac dysfunction is not proportional to that of skeletal muscle weakness. ${ }^{4}$ Furthermore, DMD-related cardiomyopathy is not similar to the other usual types of dilated cardiomyopathy in pediatric patients, with less marked left ventricular (LV) dilatation but a worse prog nosis. $^{5}$

Consequently, the prevention of cardiomyopathy stands as one of the most challenging clinical research issues in children with DMD. ${ }^{6}$ Yet routine pediatric cardiology examinations, first and foremost echocardiography, fail to determine when and to what level the cardiomyopathy will occur. ${ }^{7}$ Using conventional echocardiographic measures, most studies have struggled to prove drugs' efficacy on DMD cardiomyopathy onset and progression rate. The drugs include angiotensin-converting enzyme inhibitors, ${ }^{8} \quad \beta$-blockers, ${ }^{9,10}$ and corticosteroids. $^{11}$ In the modern era, pediatric DMD drug trials require reliable and noninvasive cardiac biomarkers. Currently available tools to evaluate cardiac function may not be very specific (biological blood tests), difficult to perform in pediatric patients (cardiovascular magnetic resonance [CMR] imaging), or too invasive (myocardial biopsy).

Among the new echocardiography techniques, speckle-tracking echocardiographic (STE) imaging, or two-dimensional (2D) strain, has emerged as an interesting noninvasive functional biomarker in pediatric cardiology ${ }^{12}$ and has also been recently considered in the early detection of DMD cardiomyopathy. ${ }^{4}$ STE imaging evaluates myocardial function with a dynamic regionalized analysis of the overall ventricular contraction. This technique measures localized myocardial movements of natural acoustic markers, also called speckles. ${ }^{13}$ STE imaging supposedly allows a rapid, precise, and objective assessment of segmental and global myocardial function in three displacements: longitudinal, radial, and circumferential. ${ }^{14}$ Several pediatric studies have pointed out the ability of STE analysis to detect preclinical myocardial dysfunction, such as after anthracycline chemotherapy, ${ }^{15}$ septic shock, ${ }^{16}$ ischemic cardiopathy, ${ }^{17}$ dilated cardiomyopathy, ${ }^{18}$ and heart transplantation. ${ }^{19}$

Similarly, recent studies with small cohorts or retrospective data suggested that STE strain was altered before the onset of DMDrelated cardiomyopathy in animal models ${ }^{20,21}$ as well as in children with DMD. ${ }^{4,22,23}$ In preliminary results, we observed a significant decrease of global longitudinal LV strain by 3.5 points, that is, from a mean normal value of $-20.5 \%{ }^{24}$ to a mean value of $-17 \%$ in children with DMD. However, no data were reported from a prospective controlled study in presymptomatic children with DMD, using STE analysis in all three displacements (longitudinal, radial, and circumferential) and for both ventricles.

Therefore, we aimed to perform a complete global and segmental STE analysis of the left and right ventricles in children with DMD and to compare the results with those obtained in healthy age-matched control subjects.

\section{METHODS}

\section{Study Design and Patients}

This prospective cross-sectional study was carried out over 15 months (from May 2015 to July 2016) at three tertiary care pediatric cardiology reference centers (Montpellier University Hospital, Montpellier, France; Saint-Pierre Institute, Palavas-Les-Flots, France, and Cliniques Universitaires St-Luc, UCL University, Brussels, Belgium).

All boys aged $<18$ years with confirmed diagnoses of DMD (clinical phenotype and either skeletal muscle biopsy or genetic testing) were eligible for the study. They were screened during routine follow-up at two tertiary care national reference centers for neuromuscular diseases (France and Belgium), which systematically includes a cardiac evaluation during the annual checkup at one of the three previously mentioned pediatric cardiology centers. Muscular stage was defined as follows: presymptomatic, early ambulatory, late ambulatory, early nonambulatory, and late nonambulatory. ${ }^{25}$

The control group consisted of boys aged $<18$ years who were referred to outpatient pediatric cardiology consultation for minor symptoms (e.g., innocent murmur, chest pain, palpitations, or sports certification). Only those with normal results on physical examination, electrocardiography, and conventional echocardiography were eligible for the study. Children with any chronic disease, or under any treatment, were not included in the control group.

All children in both groups were enrolled consecutively.

\section{Conventional Echocardiography}

Echocardiographic examinations were performed using the Vivid E9 ultrasound system (GE Healthcare, Little Chalfont, United Kingdom). A single senior pediatric cardiologist with experience in STE imaging traveled to the three recruiting sites in France and Belgium to perform all of the echocardiographic examinations, following current guidelines. ${ }^{26}$ Image acquisition procedures were harmonized before the study started. The same setting was used for each ultrasound system: global gain, lateral gain, contrast, frame rates of 60 to 80 frames/sec to optimize myocardial deformation analysis, harmonic imaging, image colorizing, and probes adapted to the size and weight of the child ( 8 or $5 \mathrm{MHz}$ ). We systematically recorded three cardiac-cycle loops in the following views: apical four-, three-, and two-chamber views, parasternal short-axis view focused on the papillary muscles, right ventricular (RV) free wall on apical, and subxiphoid four-chamber views.

The following conventional LV function variables were measured: LV ejection fraction (LVEF) by the Simpson biplane method; interventricular septal diastolic diameter and LV internal diastolic diameter using $\mathrm{M}$-mode imaging; mitral inflow with peak early filling (E-wave) 


\section{HIGHLIGHTS}

- Prognosis of Duchenne muscular dystrophy (DMD) is related to cardiac dysfunction.

- Conventional echocardiography failed to prove drugs' efficacy on cardiomyopathy.

- Speckle-tracking echocardiography (STE) is a noninvasive functional biomarker

- Left ventricle STE in DMD is altered before the onset of cardiomyopathy.

- Pediatric drug trials in DMD cardiomyopathy prevention should use STE as an outcome.

and late diastolic filling (A-wave) velocities, E/A ratio, and E-wave deceleration time; early diastolic velocities of the lateral mitral annulus $\left(\mathrm{E}^{\prime}\right)$ measured by pulsed-wave Doppler tissue imaging; $\mathrm{E} / \mathrm{E}^{\prime}$ ratio; velocity of circumferential fiber shortening; and LV wall stress, determined by the pressure in the ventricle using cuff blood pressure at the time of echocardiography, the internal radius of the ventricle by M-mode imaging, and the thickness of the wall. ${ }^{27}$

The following conventional RV function variables were measured: tricuspid annular plane systolic excursion, Doppler tissue imaging tricuspid $S$ wave, Doppler tissue imaging myocardial performance index, and inferior vena cava collapse index. ${ }^{28}$

\section{STE Analysis}

Strain analysis was performed offline by an investigator who was blinded to subject information, using EchoPAC version 112 (GE Healthcare). A second analysis was performed on a sample of 25 randomly selected subjects, by the same investigator (M.V.) to assess intra observer reproducibility, and by a second investigator (C.B.) to assess interobserver reproducibility, with no access to the results of first analysis. The investigators manually traced the endocardium in end-diastole. The software detected the movement of the entire myocardial wall (from the endocardium to the epicardium) and therefore defined the areas of interest, for which the quality was considered acceptable or not. In poorly detected segments, the sonographer readjusted the endocardial contour until better detection was obtained. Whenever that was not possible, the segments in question were excluded from the analysis and were reported as "poor tracking quality" missing data.

We measured the following global and segmental STE variables: LV longitudinal, radial, and circumferential strain from the 17-segment model $^{29} ;$ RV longitudinal strain from the free wall basal, mid, and apical segments ${ }^{12}$; and peak systolic strain rate for both ventricles in all displacements. ${ }^{12}$

\section{Formal Aspects}

The study was conducted in compliance with the Good Clinical Practices protocol and Declaration of Helsinki principles. The South Mediterranean IV Ethics Committee (2014-A01764-44) in France and the UCL Ethics Committee (2016-28AVR-192) in Belgium approved the study, which was registered on ClinicalTrials.gov (NCT02418338). Informed consent was obtained from all parents or legal guardians.
Table 1 Children with DMD: clinical characteristics

\begin{tabular}{|c|c|c|}
\hline Variable & $n$ & $\%$ \\
\hline \multicolumn{3}{|l|}{ Age range $(y)$} \\
\hline $0-4$ & 1 & 3 \\
\hline $5-8$ & 13 & 36 \\
\hline $9-12$ & 11 & 30.5 \\
\hline $13-17$ & 11 & 30.5 \\
\hline \multicolumn{3}{|l|}{ Muscular stage } \\
\hline Presymptomatic & 4 & 11 \\
\hline Early ambulatory & 7 & 19 \\
\hline Late ambulatory & 6 & 17 \\
\hline Early nonambulatory & 18 & 50 \\
\hline Late nonambulatory & 1 & 3 \\
\hline \multicolumn{3}{|l|}{ Cardiovascular symptoms } \\
\hline No cardiovascular symptoms & 34 & 94 \\
\hline Exercise dyspnea & 1 & 3 \\
\hline Rest dyspnea & 0 & 0 \\
\hline Palpitations & 1 & 3 \\
\hline Weakness & 0 & 0 \\
\hline \multicolumn{3}{|l|}{ Treatment } \\
\hline No drug & 4 & 11 \\
\hline Corticosteroids & 5 & 14 \\
\hline ACE inhibitor & 6 & 17 \\
\hline$\beta$-blocker & 0 & 0 \\
\hline Corticosteroid + ACE inhibitor & 18 & 50 \\
\hline ACE inhibitor $+\beta$-blocker & 1 & 3 \\
\hline Corticosteroid + ACE inhibitor $+\beta$-blocker & 2 & 5 \\
\hline
\end{tabular}

$A C E$, Angiotensin-converting enzyme.

\section{Sample Size and Statistical Analysis}

To calculate the sample size, we hypothesized that the percentage of global longitudinal LV strain would decrease by 3.5 points, that is, from a mean normal value of $-20.5 \%$ to a mean value of $-17 \%$ in the DMD group $(S D=5) .{ }^{24}$ The value of 3.5 points was determined from our own prestudy, as no data were available in the literature at the time the study started. With $90 \%$ power, a bilateral $\alpha$ risk of $5 \%$, and potentially $5 \%$ of missing data on the primary outcome, we planned to include 36 children with DMD and 72 control subjects (1:2 case-control design).

Each child with DMD was individually matched with two control subjects according to four groups of age $(0-4,5-8,9-12$, and $13-$ 17 years). These age ranges were arbitrarily defined.

The characteristics of the children included in the study were described with proportions for categorical variables and with means and $S D$ values for continuous variables.

The comparisons of the echocardiographic parameters (conventional and speckle-tracking analyses) between children with DMD and control subjects were performed using linear mixed models. These models included a random intercept specific to matched triads. DMD and age were entered as fixed effects in models. We studied the effect of age on the evolution of longitudinal, radial, and circumferential 2D strain in children with DMD by adding an interaction term, $\mathrm{DMD} \times$ age, in the previous models. 
Table 2 Conventional echocardiographic variables

\begin{tabular}{|c|c|c|c|c|c|}
\hline \multirow[b]{2}{*}{ Variables } & \multirow{2}{*}{$\begin{array}{l}\text { Patients with DMD } \\
(n=36) \text { mean } \pm \text { SD }\end{array}$} & \multirow{2}{*}{$\begin{array}{l}\text { Control subjects } \\
(n=72) \text { mean } \pm \text { SD }\end{array}$} & \multicolumn{3}{|c|}{ Adjusted difference between groups ${ }^{*}$} \\
\hline & & & Coefficient & $95 \% \mathrm{Cl}$ & $P^{\dagger}$ \\
\hline \multicolumn{6}{|l|}{ Left ventricle } \\
\hline LVEF (\%) & $62.6 \pm 5.8$ & $63.7 \pm 5.0$ & -0.79 & -2.94 to 1.35 & .46 \\
\hline IVSd (mm) & $6.9 \pm 1.5$ & $7.1 \pm 1.4$ & -0.47 & -0.95 to 0.003 & .05 \\
\hline LVIDd (mm) & $39.4 \pm 5.9$ & $42.5 \pm 5.2$ & -4.15 & -5.84 to -2.46 & $<.001$ \\
\hline E/A ratio & $1.8 \pm 0.3$ & $2.2 \pm 0.7$ & -0.47 & -0.71 to -0.24 & $<.001$ \\
\hline E deceleration time (msec) & $136.8 \pm 25.5$ & $175.1 \pm 33.8$ & -40.48 & -53.92 to -27.05 & $<.0001$ \\
\hline$E / E^{\prime}$ ratio & $6.0 \pm 2.2$ & $5.5 \pm 1.2$ & 0.58 & -0.09 to 1.26 & .09 \\
\hline Wall stress $\left(\mathrm{g} / \mathrm{cm}^{2}\right)$ & $49.5 \pm 14.6$ & $40.5 \pm 11.9$ & 8.94 & 3.05 to 14.84 & $<.01$ \\
\hline $\operatorname{VCFc}\left(\sec ^{-1}\right)$ & $1.38 \pm 0.36$ & $1.25 \pm 0.25$ & 0.16 & 0.05 to 0.27 & $<.01$ \\
\hline \multicolumn{6}{|l|}{ Right ventricle } \\
\hline TAPSE (mm) & $19.65 \pm 3.12$ & $20.9 \pm 3.5$ & -1.44 & -2.86 to -0.02 & .05 \\
\hline S wave (DTI) (cm/sec) & $13.3 \pm 2.3$ & $13 \pm 2.1$ & 0.21 & -0.67 to 1.10 & .63 \\
\hline Myocardial performance index (DTI) & $0.36 \pm 0.13$ & $0.38 \pm 0.12$ & -0.01 & -0.06 to 0.04 & .72 \\
\hline IVC \% & $62.8 \pm 20.0$ & $66.9 \pm 15.2$ & -4.17 & -11.95 to 3.60 & .29 \\
\hline
\end{tabular}

$D T I$, Doppler tissue imaging; IVC \%, inferior vena cava collapse index; IVSd, interventricular septal diastolic diameter; LVIDd, LV internal diastolic diameter; TAPSE, tricuspid annular plane systolic excursion; VCFC, contraction velocity corrected for cardiac frequency.

${ }^{*}$ Difference between groups adjusted for age.

${ }^{\dagger}$ Difference between groups is significantly different from zero when $P<.05$ (significant $P$ values [<.05] are in boldface type).

We evaluated the reproducibility of the performed measurements by calculating intraclass correlation coefficients (ICCs), in accordance with recommendations published by Shrout and Fleiss. ${ }^{30}$ An ICC of type $(2,1)$ was used to assess inter- and intraobserver reliability, because only one investigator was responsible for the double STE analysis to assess intraobserver reliability, and a single pair of investigators produced the two analyses to assess interobserver reliability. A total of 25 subjects ( $25 \%$ of the cohort) were randomly selected from the anonymized electronic case report form, and reproducibility analyses were performed on global LV longitudinal and circumferential 2D strain. As defined by Koo and $\mathrm{Li}^{31}$ ICC values $<0.5$, between 0.5 and 0.75 , between 0.75 and 0.9 , and $>0.90$ were indicative of poor, moderate, good, and excellent reliability, respectively.

Statistical significance was set at .05, and analyses were performed using SAS version 9 (SAS Institute, Cary, NC).

\section{RESULTS}

\section{Population}

The total expected number of 108 boys was included in the study, with 36 children with DMD (mean age, $11.0 \pm 3.8$ years) and 72 age-matched healthy control subjects (mean age, $10.0 \pm$ 3.5 years).

Children with DMD were smaller than the control subjects in terms of weight $(36.8 \pm 16.2$ vs $37.9 \pm 15.3 \mathrm{~kg}, P<.01$, respectively) and height $(134.9 \pm 19.1$ vs $143.7 \pm 20.8 \mathrm{~cm}, P<.0001$, respectively). The heart rate was significantly higher in the DMD group (95.6 \pm 12.4 vs $75.4 \pm 13.0$ beats $/ \mathrm{min}, P<.0001$, respectively). Systolic blood pressure was not significantly different between the groups. Cardiovascular symptoms were reported for only two children with DMD. The muscular stage for half of the children with DMD was "early nonambulatory." The combination therapy with cor- ticosteroids and angiotensin-converting enzyme inhibitors was the most used (Table 1).

\section{Conventional Echocardiographic Variables}

The mean values of conventional echocardiographic variables were normal in the two groups and for both the left and right ventricles (Table 2). LVEF was not significantly different between groups. In greater detail, LVEF ranged from $45 \%$ to $76 \%$ (mean, $63 \pm 6 \%$ ) in the DMD group and from 55 to $76 \%$ (mean, $64 \pm 5 \%$ ) in the control group. LVEF was mildly altered $(45 \% \leq \mathrm{LVEF}<55 \%)$ in two children with DMD and always normal (LVEF $\geq 55 \%$ ) otherwise. Only three LV variables were significantly lower in the DMD group (left ventricular internal dimension in diastole, E/A ratio, and $\mathrm{E}$ deceleration time), whereas wall stress and the velocity of circumferential fiber shortening were higher. RV conventional variables were normal and not significantly different between the children with DMD and control subjects.

\section{STE Analysis}

Global LV 2D strain values were significantly worse in the DMD group for the three longitudinal $(-16.8 \pm 3.9 \%$ vs $-20.6 \pm 2.6 \%, P<.0001)$, radial $(22.7 \pm 11.3 \%$ vs $31.7 \pm 14 \%$, $P=.002)$, and circumferential $(-16.5 \pm 3.8 \%$ vs $-20.3 \pm 3.1 \%$, $P<.0001)$ displacements. The mean global values were decreased by an average of 3.6\% for longitudinal 2D strain (Table 3), $9 \%$ for radial 2D strain (Table 4), and 3.8\% for circumferential 2D strain (Table 5). Segmental LV 2D strain values were also significantly worse for the three displacements in nearly all segments. The magnitude of the difference in 2D strain between DMD and control subjects was highest in the inferolateral and anterolateral LV segments, especially in the basal area. All global and segmental 
Table 3 LV longitudinal 2D strain

\begin{tabular}{|c|c|c|c|c|c|c|c|}
\hline \multirow[b]{2}{*}{ 2D strain and strain rate variables } & \multicolumn{2}{|c|}{ Patients with DMD } & \multicolumn{2}{|c|}{ Control subjects } & \multicolumn{3}{|c|}{ Adjusted difference between groups ${ }^{*}$} \\
\hline & $n / N$ & Mean \pm SD & $n / N$ & Mean \pm SD & Coefficient & $95 \% \mathrm{Cl}$ & $P^{\dagger}$ \\
\hline \multicolumn{8}{|l|}{ Longitudinal 2D strain (\%) } \\
\hline Global & $36 / 36$ & $-16.8 \pm 3.9$ & $72 / 72$ & $-20.6 \pm 2.6$ & 3.55 & 2.32 to 4.79 & $<.0001$ \\
\hline Segment 1: basal anterior & $29 / 36$ & $-14.8 \pm 8.0$ & $69 / 72$ & $-20.1 \pm 5$ & 4.87 & 2.48 to 7.26 & .0001 \\
\hline Segment 2: basal anteroseptal & $35 / 36$ & $-16.6 \pm 4.3$ & $70 / 72$ & $-17.8 \pm 3.5$ & 0.98 & -0.53 to 2.50 & .20 \\
\hline Segment 3: basal inferoseptal & $36 / 36$ & $-16.4 \pm 3.5$ & $72 / 72$ & $-17.9 \pm 3.4$ & 1.32 & -0.03 to 2.68 & .05 \\
\hline Segment 4: basal inferior & $36 / 36$ & $-14.8 \pm 9.3$ & $70 / 72$ & $-20.5 \pm 3.5$ & 5.41 & 2.95 to 7.87 & $<.0001$ \\
\hline Segment 5: basal inferolateral & $35 / 36$ & $-10.0 \pm 11.9$ & $70 / 72$ & $-15.7 \pm 9.5$ & 5.46 & 1.18 to 9.74 & .01 \\
\hline Segment 6: basal anterolateral & $35 / 36$ & $-7.9 \pm 10.2$ & $67 / 72$ & $-14.9 \pm 7.1$ & 6.96 & 3.69 to 10.24 & $<.0001$ \\
\hline Segment 7: mid anterior & $30 / 36$ & $-16.7 \pm 6.3$ & $70 / 72$ & $-21.1 \pm 5$ & 4.02 & 1.84 to 6.19 & $<.001$ \\
\hline Segment 8: mid anteroseptal & $35 / 36$ & $-19.2 \pm 4.9$ & $70 / 72$ & $-21.1 \pm 3.4$ & 1.72 & 0.09 to 3.34 & .04 \\
\hline Segment 9: mid inferoseptal & $36 / 36$ & $-18.5 \pm 3.2$ & $72 / 72$ & $-21 \pm 3.7$ & 2.36 & 0.99 to 3.72 & .001 \\
\hline Segment 10: mid inferior & $36 / 36$ & $-17.4 \pm 7.4$ & $71 / 72$ & $-22.4 \pm 3.6$ & 4.62 & 2.53 to 6.71 & $<.0001$ \\
\hline Segment 11: mid inferolateral & $36 / 36$ & $-13.9 \pm 7.9$ & $72 / 72$ & $-18.4 \pm 4.2$ & 4.31 & 1.97 to 6.64 & $<.001$ \\
\hline Segment 12: mid anterolateral & $36 / 36$ & $-13.4 \pm 6.6$ & $70 / 72$ & $-18.9 \pm 5.4$ & 5.23 & 2.92 to 7.53 & $<.0001$ \\
\hline Segment 13: apical anterior & $28 / 36$ & $-21.4 \pm 5.5$ & $63 / 72$ & $-23.5 \pm 5.3$ & 2.06 & -0.39 to 4.51 & .10 \\
\hline Segment 14: apical septal & $34 / 36$ & $-20.8 \pm 4.8$ & $67 / 72$ & $-24.8 \pm 4.5$ & 3.88 & 1.93 to 5.84 & $<.001$ \\
\hline Segment 15: apical inferior & $30 / 36$ & $-21.6 \pm 5.4$ & $71 / 72$ & $-24.8 \pm 4.2$ & 3.01 & 1.02 to 5.01 & $<.01$ \\
\hline Segment 16: apical lateral & $31 / 36$ & $-18.9 \pm 4.2$ & $69 / 72$ & $-23.6 \pm 4.3$ & 4.49 & 2.63 to 6.34 & $<.0001$ \\
\hline Segment 17: apex & $32 / 36$ & $-20.6 \pm 4.2$ & $59 / 72$ & $-24.2 \pm 4.1$ & 3.41 & 1.62 to 5.20 & $<.001$ \\
\hline \multicolumn{8}{|c|}{ Longitudinal global strain rate (peak systolic, $\mathrm{sec}^{-1}$ ) } \\
\hline Four-chamber & $35 / 36$ & $-1.7 \pm 0.4$ & $72 / 72$ & $-1.7 \pm 0.5$ & 0.02 & -0.16 to 0.19 & .86 \\
\hline Three-chamber & $36 / 36$ & $-1.9 \pm 0.5$ & $68 / 72$ & $-1.8 \pm 0.5$ & -0.12 & -0.31 to 0.06 & .17 \\
\hline Two-chamber & $36 / 36$ & $-2.4 \pm 2.5$ & $70 / 72$ & $-1.9 \pm 0.6$ & -0.53 & -1.17 to 0.10 & .10 \\
\hline
\end{tabular}

$n$, Patients with good tracking quality; $N$, overall number of patients in each group, representing the expected number of segments for each STE analysis ( $N-n=$ "poor tracking quality" missing data).

*Difference between groups adjusted for age.

${ }^{\dagger}$ Difference between groups is significantly different from zero when $P<.05$ (significant $P[<.05]$ are in boldface type).

Table 4 LV radial 2D strain

\begin{tabular}{|c|c|c|c|c|c|c|c|}
\hline \multirow[b]{2}{*}{ 2D strain and strain rate variables } & \multicolumn{2}{|c|}{ Patients with DMD } & \multicolumn{2}{|c|}{ Control subjects } & \multicolumn{3}{|c|}{ Adjusted difference between groups ${ }^{*}$} \\
\hline & $n / N$ & Mean \pm SD & $n / N$ & Mean \pm SD & Coefficient & $95 \% \mathrm{Cl}$ & $P^{\dagger}$ \\
\hline \multicolumn{8}{|l|}{ Radial 2D strain (\%) } \\
\hline Global & $36 / 36$ & $22.7 \pm 11.3$ & $71 / 72$ & $31.7 \pm 14$ & -8.93 & -14.37 to -3.50 & .002 \\
\hline Segment 7: mid anterior & $35 / 36$ & $19.5 \pm 12.7$ & $71 / 72$ & $22.9 \pm 16.8$ & -3.59 & -10.09 to 2.91 & .27 \\
\hline Segment 8: mid anteroseptal & $35 / 36$ & $19.8 \pm 11.4$ & $71 / 72$ & $26.7 \pm 14.3$ & -7.08 & -12.38 to -1.77 & .01 \\
\hline Segment 9: mid inferoseptal & $36 / 36$ & $18.3 \pm 13.7$ & $71 / 72$ & $23.8 \pm 16.3$ & -5.70 & -12.11 to 0.71 & .08 \\
\hline Segment 10: mid inferior & $36 / 36$ & $26.4 \pm 15.9$ & $71 / 72$ & $34.6 \pm 18.9$ & -7.48 & -14.87 to -0.09 & $<.05$ \\
\hline Segment 11: mid inferolateral & $36 / 36$ & $30.0 \pm 17.0$ & $71 / 72$ & $49.9 \pm 20.1$ & -19.43 & -27.28 to -11.59 & $<.0001$ \\
\hline Segment 12: mid anterolateral & $36 / 36$ & $22.5 \pm 14.8$ & $71 / 72$ & $32.6 \pm 19.5$ & -10.10 & -17.58 to -2.64 & .01 \\
\hline Radial strain rate (peak systolic, $\mathrm{sec}^{-1}$ ) & $36 / 36$ & $2.8 \pm 0.9$ & $71 / 72$ & $3 \pm 1.10$ & -0.10 & -0.51 to 0.31 & .63 \\
\hline
\end{tabular}

$n$, Patients with good tracking quality; $N$, overall number of patients in each group, representing the expected number of segments for each STE analysis ( $N-n=$ "poor tracking quality" missing data).

${ }^{*}$ Difference between groups adjusted for age.

${ }^{\dagger}$ Difference between groups is significantly different from zero when $P<.05$ (significant $P[<.05]$ are in boldface type).

radial LV 2D strain values in children with DMD were $>18 \%$, although significantly lower than those for the control subjects (Figure 1).
When repeating the statistical analysis without the two children with mildly altered LVEFs, the results remained unchanged: the global LV 2D strain values were significantly worse in the DMD group (34 of 
Table 5 LV circumferential 2D strain

\begin{tabular}{|c|c|c|c|c|c|c|c|}
\hline \multirow[b]{2}{*}{ 2D strain and strain rate variables } & \multicolumn{2}{|c|}{ Patients with DMD } & \multicolumn{2}{|c|}{ Control subjects } & \multicolumn{3}{|c|}{ Adjusted difference between groups ${ }^{*}$} \\
\hline & $n / N$ & Mean \pm SD & $n / N$ & Mean \pm SD & Coefficient & $95 \% \mathrm{Cl}$ & $P^{\dagger}$ \\
\hline \multicolumn{8}{|l|}{ Circumferential 2D strain (\%) } \\
\hline Global & $36 / 36$ & $-16.5 \pm 3.8$ & $71 / 72$ & $-20.3 \pm 3.1$ & 3.78 & 2.44 to 5.12 & $<.0001$ \\
\hline Segment 7: mid anterior & $35 / 36$ & $-14.2 \pm 7.6$ & $71 / 72$ & $-20.1 \pm 5.1$ & 5.79 & 3.32 to 8.25 & $<.0001$ \\
\hline Segment 8: mid anteroseptal & $35 / 36$ & $-18.0 \pm 7.6$ & $71 / 72$ & $-24.3 \pm 6.1$ & 5.81 & 3.21 to 8.40 & $<.0001$ \\
\hline Segment 9: mid inferoseptal & $36 / 36$ & $-21.8 \pm 5.8$ & $71 / 72$ & $-24.6 \pm 5.0$ & 2.57 & 0.42 to 4.72 & .02 \\
\hline Segment 10: mid inferior & $36 / 36$ & $-17.4 \pm 6.6$ & $71 / 72$ & $-21.4 \pm 4.6$ & 3.91 & 1.69 to 6.12 & .001 \\
\hline Segment 11: mid inferolateral & $36 / 36$ & $-14.3 \pm 7.4$ & $71 / 72$ & $-15.4 \pm 6.0$ & 1.68 & -1.00 to 4.36 & .22 \\
\hline Segment 12: mid anterolateral & $36 / 36$ & $-12.8 \pm 6.6$ & $71 / 72$ & $-15.5 \pm 6.5$ & 3.18 & 0.55 to 5.80 & .02 \\
\hline Circumferential strain rate (peak systolic, $\mathrm{sec}^{-1}$ ) & $35 / 36$ & $-2.1 \pm 0.5$ & $71 / 72$ & $-1.9 \pm 0.4$ & -0.25 & -0.43 to -0.07 & $<.01$ \\
\hline
\end{tabular}

$n$, Patients with good tracking quality; $N$, overall number of patients in each group, representing the expected number of segments for each STE analysis ( $N-n=$ "poor tracking quality" missing data).

*Difference between groups adjusted for age.

${ }^{\dagger}$ Difference between groups is significantly different from zero when $P<.05$ (significant $P[<.05]$ are in boldface type).
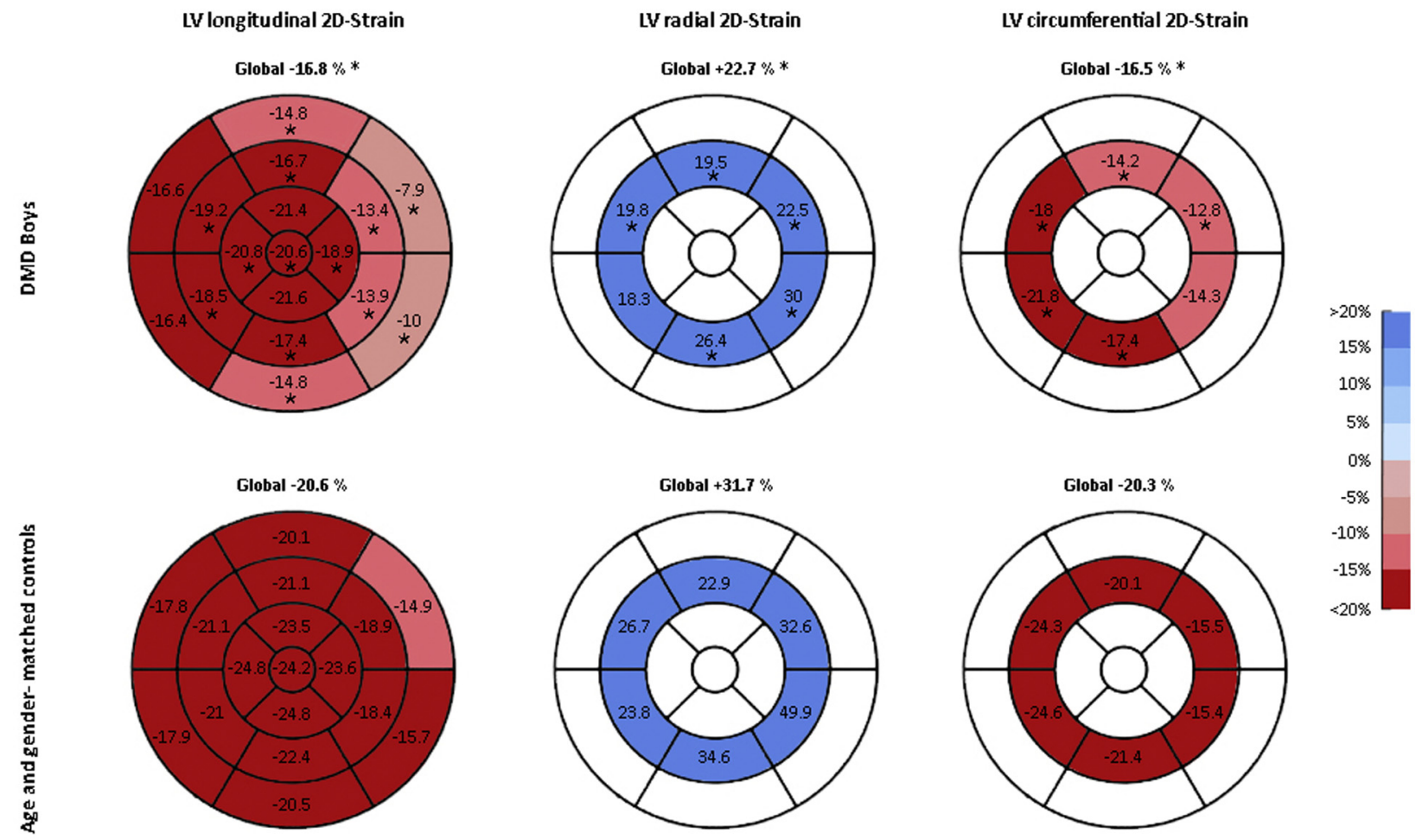

* Significant P-values (comparaison between DMD and controls)

Figure $1 \mathrm{LV}$ global and segmental 2D strain in children with DMD and control subjects. These six figures represent, for each group, longitudinal, radial, and circumferential 2D strain, using the classical blue (positive displacement) and red (negative displacement) color-coded bull's-eye plot. The DMD group is represented in the top three figures and the control group in the bottom three figures. In each strain segment of the DMD group, an asterisk indicates the existence of a significant difference with the corresponding segment of the control group.

36) for the three longitudinal $(-17 \pm 3.9 \%$ vs $-20.6 \pm 2.6 \%$, $P<.0001)$, radial $(22.4 \pm 11.6$ vs $31.7 \pm 13.7 \%, P=.003)$, and circumferential $(-16.9 \pm 3.6 \%$ vs $-20.2 \pm 3.1 \%, P<.0001)$ displacements.

We found a significant interaction of age with DMD on longitudinal global 2D strain: children with DMD had a decrease $0.34 \%$ per year more than that of the control group (slope, $0.45 \mathrm{vs} 0.11$, respectively; $P=.04$; Figure 2A). Despite apparent differences, the interaction of age with DMD on global circumferential 2D strain (Figure 2B) and global radial 2D strain (Figure 2C) was not statistically significant.

In terms of tracking quality, missing data per segment are indicated in Tables 3, 4, and 5. After removal of poorly detected segments 


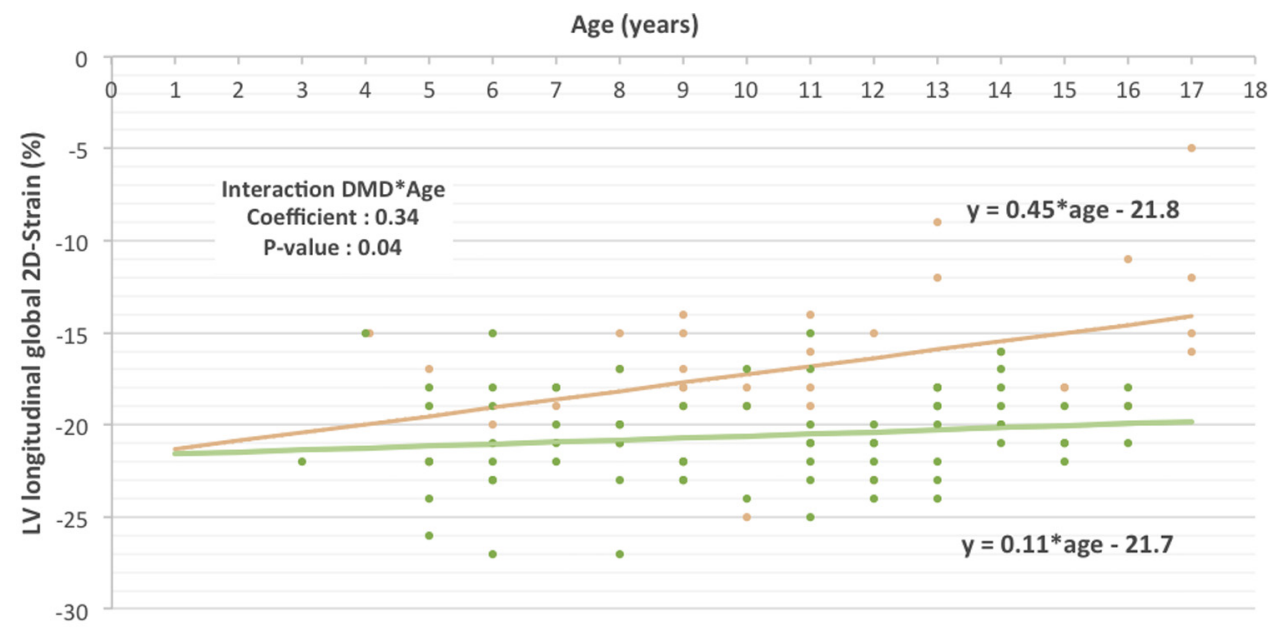

A
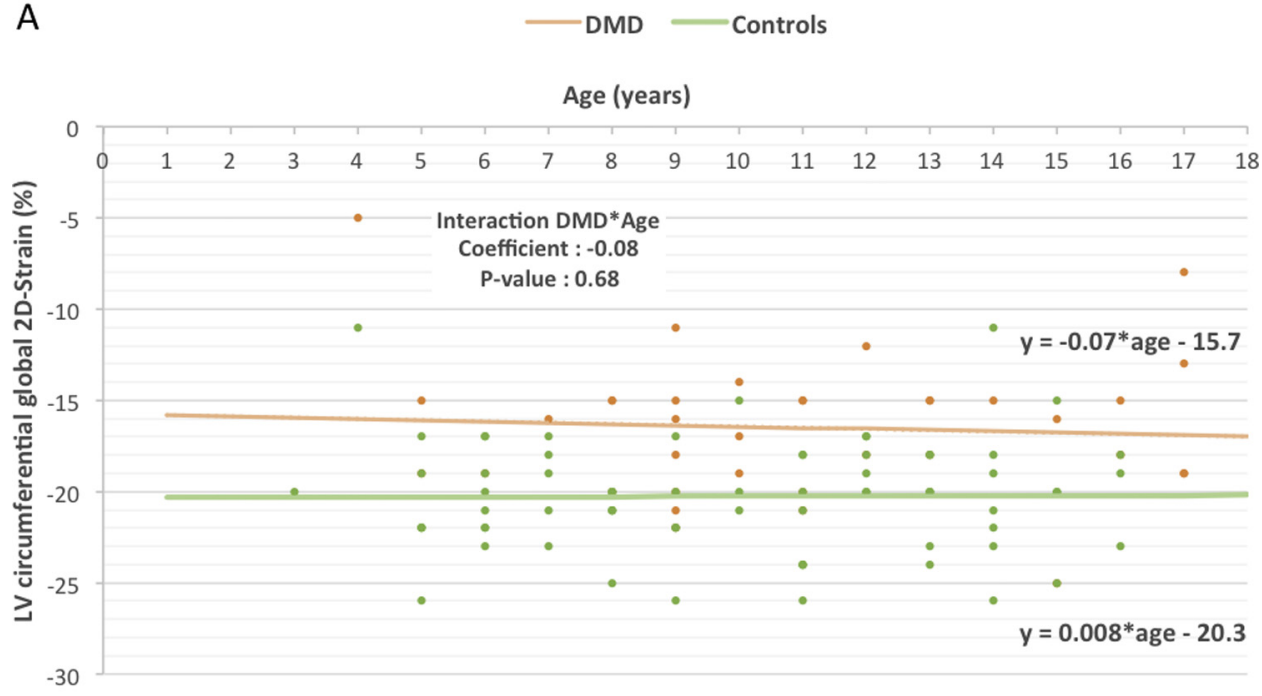

B
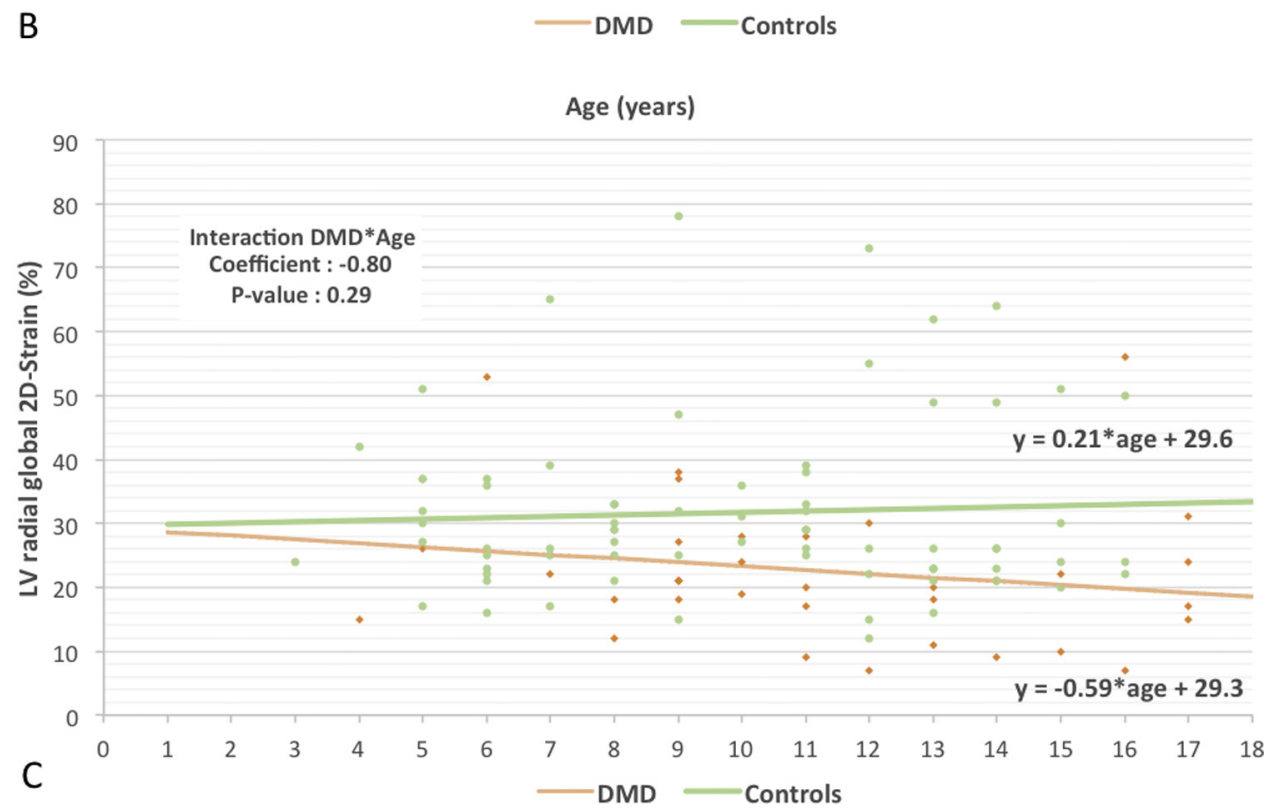

Figure 2 Effect of age on the evolution of longitudinal (A), circumferential (B), and radial (C) strain in children with DMD and control subjects. 
Table 6 RV longitudinal 2D strain

\begin{tabular}{|c|c|c|c|c|c|c|c|}
\hline \multirow[b]{2}{*}{$2 \mathrm{D}$ strain and strain rate variables } & \multicolumn{2}{|c|}{ Patients with DMD } & \multicolumn{2}{|c|}{ Control subjects } & \multicolumn{3}{|c|}{ Adjusted difference between groups ${ }^{*}$} \\
\hline & $n / N$ & Mean \pm SD & $n / N$ & Mean \pm SD & Coefficient & $95 \% \mathrm{Cl}$ & $P^{\dagger}$ \\
\hline \multicolumn{8}{|l|}{ Free wall 2D strain in apical four-chamber view (\%) } \\
\hline Global & $36 / 36$ & $-24.7 \pm 6.3$ & $71 / 72$ & $-26.2 \pm 5.0$ & 1.17 & -1.39 to 3.73 & .36 \\
\hline Basal & $22 / 36$ & $-30.2 \pm 6.9$ & $59 / 72$ & $-27.8 \pm 7.6$ & -2.64 & -6.16 to 0.88 & .14 \\
\hline Mid & $21 / 36$ & $-28.3 \pm 5.0$ & $60 / 72$ & $-28.7 \pm 6.2$ & 0.09 & -2.71 to 2.90 & .95 \\
\hline Apical & $22 / 36$ & $-18 \pm 6.8$ & $59 / 72$ & $-22.1 \pm 7.0$ & 3.84 & 0.42 to 7.26 & .03 \\
\hline $\begin{array}{l}\text { Free wall strain rate in apical four-chamber view } \\
\text { (peak systolic, } \sec ^{-1} \text { ) }\end{array}$ & $23 / 36$ & $-2.4 \pm 0.7$ & $61 / 72$ & $-2.2 \pm 0.6$ & -0.20 & -0.51 to 0.10 & .18 \\
\hline \multicolumn{8}{|l|}{$\begin{array}{l}\text { Free wall 2D strain in subxiphoid four-chamber } \\
\text { view (\%) }\end{array}$} \\
\hline Global & $33 / 36$ & $-21.9 \pm 7.8$ & $64 / 72$ & $-22.9 \pm 6.9$ & 0.70 & -2.28 to 3.69 & .64 \\
\hline Basal & $32 / 36$ & $-24.4 \pm 10.4$ & $62 / 72$ & $-26.7 \pm 10.2$ & 1.76 & -2.39 to 5.92 & .40 \\
\hline Mid & $33 / 36$ & $-22.5 \pm 8.5$ & $64 / 72$ & $-23.3 \pm 8$ & 0.50 & -2.96 to 2.97 & .77 \\
\hline Apical & $33 / 36$ & $-19.1 \pm 8.6$ & $61 / 72$ & $-18.9 \pm 6.9$ & -0.40 & -3.65 to 2.85 & .80 \\
\hline $\begin{array}{l}\text { Free wall strain rate in subxiphoid four-chamber } \\
\text { view (peak systolic, } \mathrm{sec}^{-1} \text { ) }\end{array}$ & $33 / 36$ & $-2.6 \pm 0.9$ & $64 / 72$ & $-2.4 \pm 0.8$ & -0.27 & -0.61 to 0.07 & .11 \\
\hline
\end{tabular}

$n$, Patients with good tracking quality; $N$, overall number of patients in each group, representing the expected number of segments for each STE analysis ( $N-n=$ "poor tracking quality" missing data).

*Difference between groups adjusted for age.

${ }^{\dagger}$ Difference between groups is significantly different from zero when $P<.05$; significant $P$ values $(<.05)$ are in boldface type.

(e.g., missing data) from the analysis, the global longitudinal, radial, and circumferential LV 2D strain analyses could be calculated in almost all patients: we reported no missing data for global longitudinal LV strain in both groups and $1.4 \%$ missing data for radial and circumferential LV strain analyses in the control group only.

The RV free wall longitudinal 2D strain analyses were not significantly different between children with DMD and control subjects, except for a significantly worse value in the DMD apical segment on the apical intercostal four-chamber view $(-18 \pm 6.8 \%$ vs $-22.1 \pm 7 \%$, respectively, $P=.03$; Table 6).

The strain rate analyses were not significantly different between children with DMD and control subjects, whatever ventricle, segment, or view was studied.

\section{Inter- and Intraobserver Reproducibility}

Intraobserver reliability was good, with an ICC of 0.77 (95\% CI, 0.55-0.89) for longitudinal global 2D strain and an ICC of 0.78 (95\% CI, 0.52-0.91) for circumferential global 2D strain. Interobserver reliability was relatively good, with an ICC of 0.68 (95\% CI, 0.41-0.84) for longitudinal global 2D strain and an ICC of 0.62 (95\% CI, 0.30-0.81) for circumferential global 2D strain.

\section{DISCUSSION}

This multicenter prospective controlled study of 108 children demonstrated that global left ventricular 2D strain in boys with DMD was significantly altered with STE analysis, before the onset of relevant patterns of cardiomyopathy. The expected number of 36 boys with DMD and 72 healthy age-matched control subjects were included in the study. A significant difference in the primary outcome was observed, with a mean difference of $3.6 \%$ for global longitudinal LV strain, between children with DMD and matched control subjects. Moreover, global LV strain was also altered in the radial and circumferential displacements, with mean differences of $9 \%$ and $3.8 \%$, respectively, between children with DMD and matched control subjects.

This study confirms recently reported preliminary results $4,22,23$ using, for the first time, a rigorous evaluation of LV and RV STE strain in patients with DMD. Indeed, Spurney et al. ${ }^{4}$ used STE imaging to identify subclinical myocardial dysfunction, showing a decrease in circumferential and longitudinal strain, in a cohort of 33 children with DMD. However, those authors used data from 33 retrospective agematched control subjects and did not perform a complete STE analysis in all displacements. Recently, a retrospective study by Taqatqa et al. ${ }^{22}$ analyzed circumferential and longitudinal STE strain in 19 children with DMD versus 16 control subjects and found similar results, with an even larger magnitude of difference (global longitudinal STE strain, $-18.8 \pm 3.0 \%$ vs $-13.6 \pm 5.0 \%$; $P=.001$ ). A noncontrolled study by Soslow et al. ${ }^{23}$ showed that circumferential STE strain and CMR strain correlated moderately well in 20 patients with DMD $(r=0.64, P=.02)$ and revealed a trend toward reduced STE strain in patients with late gadolinium enhancement $(-19.4 \pm 3.1 \%$ vs $-15.9 \pm 3.7 \%, P=.09)$. Therefore, our study confirmed these results with a higher level of evidence using, for the first time, a prospective clinical trial controlled study design, with an age-matched control group.

The decrease of global LV longitudinal strain with age in children with DMD was $0.34 \%$ per year more marked than that in control subjects. The association between age and strain remains limited by the design of this cross-sectional study. Therefore, we plan to follow this cohort to confirm that strain declines with age in children with DMD. Ultimately, defining a strain threshold would help clinicians decide on when to start intervention.

Using conventional echocardiography, a recent study revealed a potential novel biomarker of DMD-related cardiomyopathy by 
identifying abnormal LV tonic contraction in 70 pediatric patients with DMD. ${ }^{32}$ Our results suggest that speckle-tracking analysis in children with DMD is more accurate than conventional echocardiography to identify areas of myocardial dysfunction and, therefore, early cardiomyopathy onset. Although 2D strain was significantly worse in patients with DMD there was no difference in strain rate. Indeed, few studies used strain rate analysis in clinical practice to measure LV function in children, and a recent meta-analysis showed that the ranges for strain rate were wide and should be used with caution. $^{33}$

We identified differences in segmental 2D strain with significantly worse values in the inferolateral and anterolateral segments, especially in the basal area. These results are superimposable with those from a study from Bilchick et al., ${ }^{34}$ in which the overall CMR scar prevalence in the inferior, inferolateral, and anterolateral segments was eight times higher than in inferoseptal, anteroseptal, and anterior segments.

In our study, RV function in children with DMD was normal and similar to that of control subjects on both conventional echocardiographic and STE analyses. Physiologically, RV function is related to respiratory status in DMD. ${ }^{35}$ Therefore, normal RV function may reflect the current efficient preventive and active support of DMD respiratory failure (physiotherapy, noninvasive ventilation). However, in our study, STE analysis did not identify any specific RV cardiomyopathy patterns. The only altered RV segment was the apex, but this area might also reflect LV function, as the apex is contiguous to both ventricles. Little is known from the literature about RV function in DMD, but some recent studies have suggested the existence of an early RV fibrosis in mdx mice ${ }^{36}$ and DMD patients. ${ }^{37}$ In our study, conventional echocardiographic and STE evaluation of the right ventricle may have been technically difficult, and minor changes might not have been detected. Further specific works on RV function in DMD are therefore necessary, using both STE and CMR analyses.

This study was performed among children with DMD presenting no evidence of significant DMD-related cardiomyopathy and therefore without any relevant symptoms of heart failure and with normal or subnormal systolic function on conventional echocardiography. Thus, the main result of this study, that is, altered LV strain despite a normal or mildly altered ejection fraction, represents an important perspective for future pediatric drug trials in DMD-related cardiomyopathy prevention. ${ }^{6}$ Indeed, reliable and noninvasive biomarkers are necessary for pediatric cardiology trials. CMR tends to be considered as the most reliable examination in the assessment of DMD-related cardiomyopathy, allowing accurate volumetric measures and late gadolinium enhancement of areas with edema and fibrosis. $6,7,23$ However, CMR requires general anesthesia or sedation in children, administration of gadolinium-based contrast, with potential accumulation in the brain. ${ }^{38,39}$ Some centers are now using "real-time" CMR sequences, which do not require sedation, and in some cases, assessment of diffuse myocardial fibrosis can be performed without injection of a gadolinium-based contrast agent. Nevertheless, current guidelines in DMD still recommend echocardiography as the preferred imaging modality to evaluate myocardial function. ${ }^{6}$ As opposed to adult patients with DMD, in whom the quality of echocardiographic images is often hampered by scoliosis, our study demonstrated that LV STE analysis in children with DMD was feasible, with excellent tracking quality.

This study included very few untreated patients. Many questions remain about the commonly used drugs in DMD, such as angiotensin-converting enzyme inhibitors, angiotensin II receptor blockers, $\beta$-blockers, and glucocorticoids. ${ }^{2,11,40,41}$ Whether these agents should be started earlier, such as at the time of DMD diagnosis, or before the onset of decreased cardiac function, or even used together, remains unclear. Therefore, our results confirm that these issues could be investigated using STE analysis, as recently suggested. ${ }^{6}$ Indeed, a recent randomized prospective study of mineralocorticoid receptor antagonism with eplerenone demonstrated an attenuation of the decrease in LV function, measured by circumferential strain. ${ }^{42,43}$ Speckle-tracking could also be used as an outcome in the current DMD drug trials, such as those testing phosphodiesterase- 5 inhibitors ${ }^{44}$ or COX-inhibiting nitric oxide donators. $^{45}$

\section{Study Limitations}

The control group was screened from the outpatient pediatric cardiology consultation; however, we applied very strict criteria to identify a population as healthy as possible.

We used a single ultrasound system and its dedicated STE software and therefore did not analyze data from other ultrasound systems, STE vendors, or vendor-independent software.

Because of the study design and sample size, we could not analyze the effect of some relevant clinical data (e.g., treatment duration, genetic background) on STE results.

Our results suggest that global longitudinal 2D strain could be used as a noninvasive outcome in future clinical trials for children with DMD. However, further studies will have to demonstrate that speckle-tracking analysis represents a reliable surrogate end point for heart failure in this population.

\section{CONCLUSION}

In children with DMD, global LV 2D strain was significantly decreased for longitudinal, radial, and circumferential displacements, before the onset of DMD-related cardiomyopathy. The inferolateral and anterolateral segments were the most impaired, especially in the basal area. Moreover, children with DMD presented a significant decrease in global LV longitudinal 2D strain with age. RV function measured on conventional echocardiography and STE analysis was normal in children with DMD and similar to that in control subjects

The existence of altered LV strain despite a normal or mildly altered LVEF represents an important perspective for future pediatric drug trials in DMD-related cardiomyopathy prevention. Further prospective cohort studies need to be performed to confirm that global longitudinal LV 2D strain represents a reliable surrogate end point for heart failure in patients with DMD.

\section{ACKNOWLEDGMENTS}

We thank Sebastien Mounier (graphic designing) and Anne Cadene (study monitoring).

\section{REFERENCES}

1. Guiraud S, Aartsma-Rus A, Vieira NM, Davies KE, van Ommen GJ, Kunkel LM. The pathogenesis and therapy of muscular dystrophies Annu Rev Genomics Hum Genet 2015;16:281-308. 
2. D'Amario D, Amodeo A, Adorisio R, Tiziano FD, Leone AM, Perri G, et al. A current approach to heart failure in Duchenne muscular dystrophy. Heart 2017;103:1770-9.

3. Kamdar F, Garry DJ. Dystrophin-deficient cardiomyopathy. J Am Coll Cardiol 2016;67:2533-46.

4. Spurney CF, McCaffrey FM, Cnaan A, Morgenroth LP, Ghelani SJ, Gordish-Dressman $\mathrm{H}$, et al. Feasibility and reproducibility of echocardiographic measures in children with muscular dystrophies. J Am Soc Echocardiogr 2015;28:999-1008.

5. Connuck DM, Sleeper LA, Colan SD, Cox GF, Towbin JA, Lowe AM, et al. Characteristics and outcomes of cardiomyopathy in children with Duchenne or Becker muscular dystrophy: a comparative study from the Pediatric Cardiomyopathy Registry. Am Heart J 2008;155 998-1005.

6. McNally EM, Kaltman JR, Benson DW, Canter CE, Cripe LH, Duan D, et al. Contemporary cardiac issues in Duchenne muscular dystrophy Working Group of the National Heart, Lung, and Blood Institute in collaboration with Parent Project Muscular Dystrophy. Circulation 2015;131 1590-8.

7. Spurney C, Shimizu R, Morgenroth LP, Kolski H, Gordish-Dressman H, Clemens PR, et al. Cooperative International Neuromuscular Research Group Duchenne Natural History Study demonstrates insufficient diag nosis and treatment of cardiomyopathy in Duchenne muscular dystrophy Muscle Nerve 2014;50:250-6.

8. Duboc D, Meune C, Lerebours G, Devaux JY, Vaksmann G, Becane HM. Effect of perindopril on the onset and progression of left ventricular dysfunction in Duchenne muscular dystrophy. J Am Coll Cardiol 2005; 45:855-7.

9. Viollet L, Thrush PT, Flanigan KM, Mendell JR, Allen HD. Effects of angiotensin-converting enzyme inhibitors and/or beta blockers on the cardiomyopathy in Duchenne muscular dystrophy. Am J Cardiol 2012;110 98-102.

10. Ogata H, Ishikawa Y, Ishikawa Y, Minami R. Beneficial effects of betablockers and angiotensin-converting enzyme inhibitors in Duchenne muscular dystrophy. J Cardiol 2009;53:72-8.

11. Matthews E, Brassington R, Kuntzer T, Jichi F, Manzur AY. Corticosteroids for the treatment of Duchenne muscular dystrophy. Cochrane Database Syst Rev 2016;CD003725.

12. Levy PT, Sanchez Mejia AA, Machefsky A, Fowler S, Holland MR, Singh GK. Normal ranges of right ventricular systolic and diastolic strain measures in children: a systematic review and meta-analysis. J Am Soc Echocardiogr 2014;27:549-60.e3.

13. D'Hooge J, Heimdal A, Jamal F, Kukulski T, Bijnens B, Rademakers F, et al Regional strain and strain rate measurements by cardiac ultrasound: principles, implementation and limitations. Eur J Echocardiogr 2000;1:154-70.

14. Mondillo S, Galderisi M, Mele D, Cameli M, Lomoriello VS, Zaca V, et al. Speckle-tracking echocardiography: a new technique for assessing myocardial function. J Ultrasound Med 2011;30:71-83.

15. Negishi K, Negishi T, Haluska BA, Hare JL, Plana JC, Marwick TH. Use of speckle strain to assess left ventricular responses to cardiotoxic chemotherapy and cardioprotection. Eur Heart J Cardiovasc Imaging 2014;15 324-31.

16. Basu S, Frank LH, Fenton KE, Sable CA, Levy RJ, Berger JT. Two-dimensional speckle tracking imaging detects impaired myocardial performance in children with septic shock, not recognized by conventional echocardiography. Pediatr Crit Care Med 2012;13:259-64.

17. Cabrera AG, Chen DW, Pignatelli RH, Khan MS, Jeewa A, Mery CM, et al. Outcomes of anomalous left coronary artery from pulmonary artery repair: beyond normal function. Ann Thorac Surg 2015:99:1342-7.

18. Friedberg MK, Slorach C. Relation between left ventricular regional radial function and radial wall motion abnormalities using two-dimensional speckle tracking in children with idiopathic dilated cardiomyopathy. Am J Cardiol 2008;102:335-9.

19. Mingo-Santos S, Monivas-Palomero V, Garcia-Lunar I, Mitroi CD, Goiri golzarri-Artaza J, Rivero B, et al. Usefulness of two-dimensional strain parameters to diagnose acute rejection after heart transplantation. J Am Soc Echocardiogr 2015;28:1149-56.
20. Spurney C, Yu Q, Nagaraju K. Speckle tracking analysis of the left ventricular anterior wall shows significantly decreased relative radial strain patterns in dystrophin deficient mice after 9 months of age. PLoS Curr 2011;3:RRN1273.

21. Takano H, Fujii Y, Yugeta N, Takeda S, Wakao Y. Assessment of left ventricular regional function in affected and carrier dogs with Duchenne muscular dystrophy using speckle tracking echocardiography. BMC Cardiovasc Disord 2011;11:23.

22. Taqatqa A, Bokowski J, Al-Kubaisi M, Khalil A, Miranda C, Alaksham H, et al. The use of speckle tracking echocardiography for early detection of myocardial dysfunction in patients with Duchenne muscular dystrophy. Pediatr Cardiol 2016;37:1422-8.

23. Soslow JH, Xu M, Slaughter JC, Stanley M, Crum K, Markham LW, et al. Evaluation of echocardiographic measures of left ventricular function in patients with Duchenne muscular dystrophy: assessment of reproducibility and comparison to cardiac magnetic resonance imaging. J Am Soc Echocardiogr 2016;29:983-91.

24. Jashari H, Rydberg A, Ibrahimi P, Bajraktari G, Kryeziu L, Jashari F, et al Normal ranges of left ventricular strain in children: a meta-analysis. Cardiovasc Ultrasound 2015;13:37.

25. Birnkrant DJ, Bushby K, Bann CM, Apkon SD, Blackwell A, Brumbaugh D, et al. Diagnosis and management of Duchenne muscular dystrophy, part 1: diagnosis, and neuromuscular, rehabilitation, endocrine, and gastrointestinal and nutritional management. Lancet Neurol 2018;17: 251-67.

26. Lopez L, Colan SD, Frommelt PC, Ensing G, Kendall K, Younoszai AK, et al. Recommendations for quantification methods during the perfor mance of a pediatric echocardiogram: a report from the Pediatric Measurements Writing Group of the American Society of Echocardiography Pediatric and Congenital Heart Disease Council. J Am Soc Echocardiogr 2010;23:465-95.

27. Colan SD, Borow KM, Neumann A. Left ventricular end-systolic wall stress-velocity of fiber shortening relation: a load-independent index of myocardial contractility. J Am Coll Cardiol 1984;4:715-24.

28. Rudski LG, Lai WW, Afilalo I, Hua L, Handschumacher MD, Chandrasekaran K, et al. Guidelines for the echocardiographic assessment of the right heart in adults: a report from the American Society of Echocardiography endorsed by the European Association of Echocardiography, a registered branch of the European Society of Cardiology, and the Canadian Society of Echocardiography. J Am Soc Echocardiogr 2010;23: 685-713.

29. Voigt JU, Pedrizzetti G, Lysyansky P, Marwick TH, Houle H, Baumann R, et al. Definitions for a common standard for 2D speckle tracking echocar diography: consensus document of the EACVI/ASE/Industry Task Force to Standardize Deformation Imaging. J Am Soc Echocardiogr 2015;28: 183-93.

30. Shrout PE, Fleiss JL. Intraclass correlations: uses in assessing rater reliability. Psychol Bull 1979;86:420-8.

31. Koo TK, Li MY. A guideline of selecting and reporting intraclass correlation coefficients for reliability research. J Chiropr Med 2016;15:155-63.

32. Su JA, Ramos-Platt L, Menteer J. Left ventricular tonic contraction as a novel biomarker of cardiomyopathy in Duchenne muscular dystrophy. Pediatr Cardiol 2016:37:678-85.

33. Levy PT, Machefsky A, Sanchez AA, Patel MD, Rogal S, Fowler S, et al Reference ranges of left ventricular strain measures by two-dimensional speckle-tracking echocardiography in children: a systematic review and meta-analysis. J Am Soc Echocardiogr 2016;29:209-25.e6.

34. Bilchick KC, Salerno M, Plitt D, Dori Y, Crawford TO, Drachman D, et al Prevalence and distribution of regional scar in dysfunctional myocardial segments in Duchenne muscular dystrophy. J Cardiovasc Magn Reson 2011;13:20

35. Mehmood M, Ambach SA, Taylor MD, Jefferies JL, Raman SV, Taylor RJ, et al. Relationship of right ventricular size and function with respiratory status in Duchenne muscular dystrophy. Pediatr Cardiol 2016;37:878-83.

36. Meyers TA, Townsend D. Early right ventricular fibrosis and reduction in biventricular cardiac reserve in the dystrophin-deficient mdx heart. Am ] Physiol Heart Circ Physiol 2015;308:H303-15. 
37. Mehmood M, Hor KN, Al-Khalidi HR, Benson DW, Jefferies JL, Taylor MD, et al. Comparison of right and left ventricular function and size in Duchenne muscular dystrophy. Eur J Radiol 2015;84:1938-42.

38. Siegel B, Olivieri L, Gordish-Dressman H, Spurney CF. Myocardial strain us ing cardiac MR feature tracking and speckle tracking echocardiography in Duchenne muscular dystrophy patients. Pediatr Cardiol 2018;39:478-83.

39. Malayeri AA, Brooks KM, Bryant LH, Evers R, Kumar P, Reich DS, et al. National Institutes of Health perspective on reports of gadolinium deposition in the brain. J Am Coll Radiol 2016;13:237-41.

40. Duboc D, Meune C, Pierre B, Wahbi K, Eymard B, Toutain A, et al. Perindopril preventive treatment on mortality in Duchenne muscular dystrophy: 10 years' follow-up. Am Heart J 2007; 154:596-602.

41. Matsumura T, Tamura T, Kuru S, Kikuchi Y, Kawai M. Carvedilol can prevent cardiac events in Duchenne muscular dystrophy. Intern Med 2010; 49:1357-63.
42. Raman SV, Hor KN, Mazur W, Halnon NJ, Kissel JT, He X, et al. Eplere none for early cardiomyopathy in Duchenne muscular dystrophy: a randomised, double-blind, placebo-controlled trial. Lancet Neurol 2015;14 $153-61$.

43. Raman SV, Hor KN, Mazur W, He X, Kissel JT, Smart S, et al. Eplerenone for early cardiomyopathy in Duchenne muscular dystrophy: results of a two-year open-label extension trial. Orphanet J Rare Dis 2017;12:39.

44. Nelson MD, Rader F, Tang X, Tavyev J, Nelson SF, Miceli MC, et al. PDE5 inhibition alleviates functional muscle ischemia in boys with Duchenne muscular dystrophy. Neurology 2014;82:2085-91.

45. Uaesoontrachoon K, Quinn JL, Tatem KS, Van Der Meulen JH, Yu Q, Phadke A, et al. Long-term treatment with naproxcinod significantly improves skeletal and cardiac disease phenotype in the mdx mouse model of dystrophy. Hum Mol Genet 2014;23:3239-49.

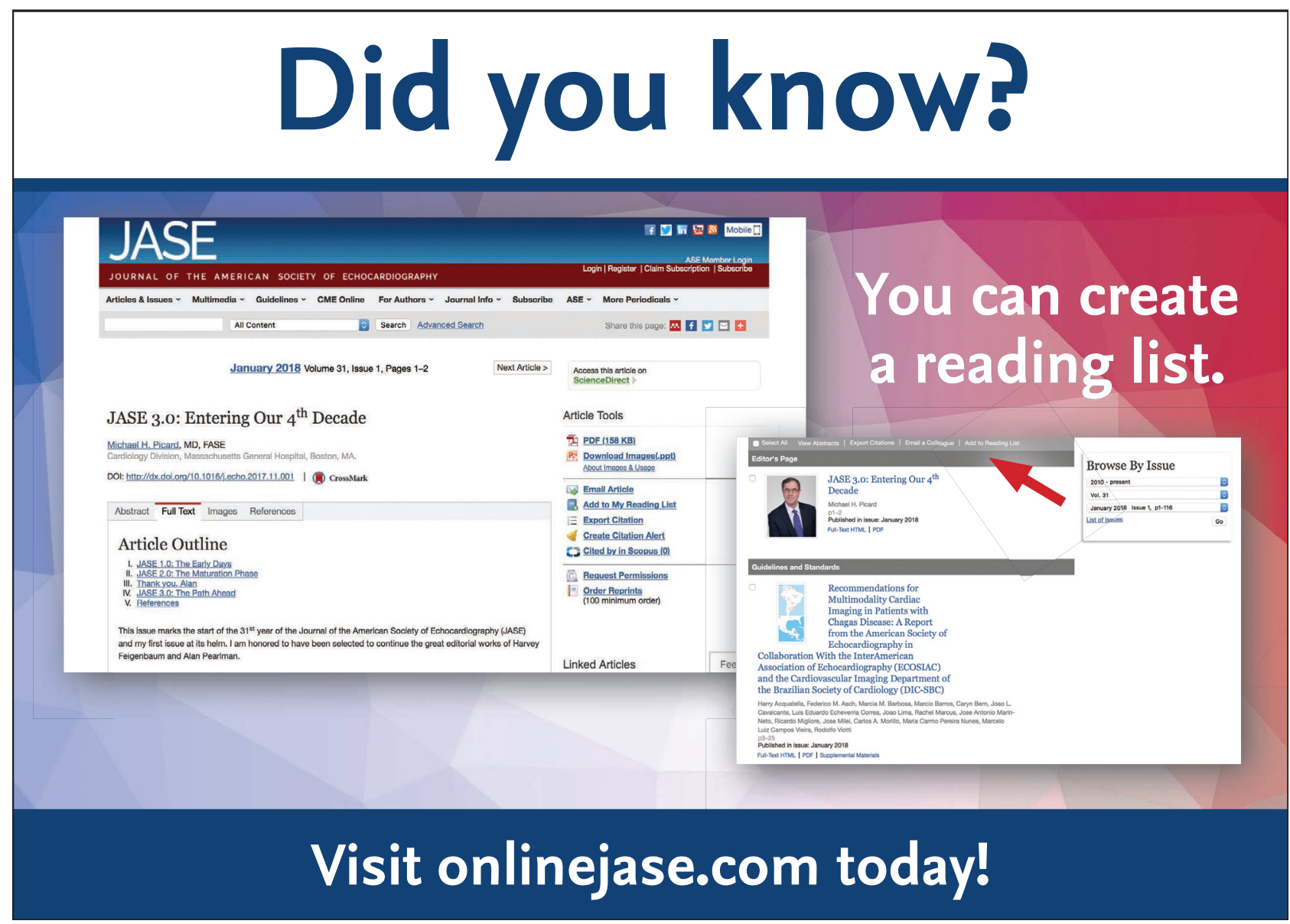

